\title{
Caminhos de um manuscrito setecentista: da Vila Real do Sabará à contemporaneidade
}

\section{Paths of an eighteenth-century manuscript: from Vila Real do Sabará to contemporaneity}

\author{
Maria de Fátima Nunes Madeira* \\ Universidade de São Paulo, São Paulo, SP, Brasil \\ Marcelo Módolo** \\ Universidade de São Paulo, São Paulo, SP, Brasil
}

\begin{abstract}
Resumo: O caminho percorrido por um manuscrito, desde a sua produção, até chegar à contemporaneidade, pode revelar marcas de ações políticas que decidiram pela sua preservação. Para ilustrar esse pressuposto, apresenta-se a Carta Régia ao Juiz e officiaes da Camara para a contribuiçaõ do subsidio voluntario, de 1755, e mais especificamente sua cópia, de 1777. Logo na criação do documento, notam-se preocupações com a sua longevidade e com a segurança de sua circulação, a partir da análise codicológica do manuscrito. O catálogo Coleção Alberto Lamego, do IEB - Instituto de Estudos Brasileiros - configura-se como instrumento fundamental para a análise das fases de transmissão desse manuscrito, pois indica lugares de pousos em arquivos onde também se evidenciam esforços para a sua preservação e divulgação. Os estudos paleográficos e diplomáticos fornecem informações que permitem deduzir do texto e do testemunho a sua autoria, datação e observância de certas fórmulas peculiares dessa espécie documental, tornando possível a verificação de sua autenticidade e genuinidade, características imprescindíveis para que a edição semidiplomática do manuscrito possa ser utilizada como fonte documental segura para futuras pesquisas. Colecionadores, arquivistas, filólogos e demais pesquisadores são coautores nessa importante tarefa de transmitir documentos a gerações futuras.
\end{abstract}

Palavras-chave: Filologia Portuguesa. Carta Régia. Edição semidiplomática.

Fonte documental.

\begin{abstract}
The path followed by a manuscript from its production to the contemporaneity, can indicate marks of political actions that decided for its preservation. In order to illustrate this assumption, we present the Royal Charter to the Chamber Judge and officials for the contribution of the voluntary subsidy of 1755 and more specifically its copy, from 1777. From the codicological analysis of the manuscript, it is possible to observe, since its production, its longevity and the safety with its circulation. The catalog Alberto Lamego's Collection, by IEB - Instituto de Estudos Brasileiros - is a fundamental instrument for the analysis of the manuscript's transmission phases as it indicates places of landings in archives where efforts are also evidenced for its preservation and
\end{abstract}

\footnotetext{
* Mestranda no programa de Filologia e Língua Portuguesa do Departamento de Letras Clássicas e Vernáculas da Faculdade de Filosofia, Letras e Ciências Humanas da Universidade de São Paulo, São Paulo, SP, Brasil; fatima.madeira@usp.br

** Professor-doutor do Departamento de Letras Clássicas e Vernáculas da Faculdade de Filosofia, Letras e Ciências Humanas da Universidade de São Paulo, São Paulo, SP, Brasil, e bolsista de produtividade em pesquisa do CNPq - nível 2 (processo número 308793/2019-6); modolo@usp.br
} 
dissemination. Paleographic and diplomatic studies provide information that allows us to deduct its authorship from the text and testimony, date and certain individual formulas of these documentary species, making it possible to verify its authenticity and genuineness. All those are essential characteristics for the semidiplomatic edition can be used as a safe documentary source for future research. Collectors, archivists, philologists and other researchers are co-authors in this important task of transmitting documents to future generations.

Keywords: Portuguese philology. Royal charter. Semidiplomatic edition. Manuscript transmission. Documental source.

\section{INTRODUÇÃO}

A cópia da carta régia de 1755 , corpus desta pesquisa, selecionada pelas propriedades diplomáticas que a distinguem como fonte documental, será apresentada sob a perspectiva da curadoria textual, metodologia pela qual o filólogo aproxima o texto e o leitor, distanciados um do outro pela ação do tempo. O texto, como bem cultural e patrimonial, razão de ser da filologia, será restituído por meio da edição semidiplomática do testemunho, antecedida pela edição fac-similar.

Primeiramente, levando-se em conta que cada texto requer um tratamento específico para ser entendido e publicado, e por tratar-se de uma cópia, será apresentada uma descrição elementar do manuscrito: o tema da carta régia na sua origem e sua função no momento do seu traslado; sua forma, de acordo com o estágio de transmissão ou gradação de ingenuidade documental, isto é, o grau de relação entre o documento e sua matriz (Bellotto, 2002, p. 105); e a constatação da existência de um segundo testemunho desse manuscrito no Arquivo Histórico Ultramarino.

Em seguida, serão abordadas relevantes informações para o estudo da transmissão do testemunho, a partir da história do acervo Alberto Lamego, acessível no IEB - Instituto de Estudos Brasileiros da USP, do qual faz parte o documento. Por constituir-se de um texto preservado em manuscrito, a cópia da carta régia, corpus desta pesquisa, receberá uma cuidadosa descrição codicológica, com base em seu suporte material.

A análise paleográfica seguirá o tríplice método de Contreras (1994), baseado na distinção entre leitura, análise e identidade com a história da escrita, que tornam possível a verificação da autenticidade do documento, além de permitir uma reconstituição segura do texto, a mais próxima possível de sua forma genuína.

A análise diplomática debaterá a estrutura formal do documento e a descrição das formas de transmissão da carta régia de 1755, uma espécie documental das mais relevantes que circularam entre a metrópole portuguesa e a colônia brasileira. Com a análise de sua fórmula peculiar, espera-se conjecturar sobre a natureza jurídica do documento e sobre a sua força probatória (Bellotto, 2002).

Por fim, um breve contexto histórico destacará do texto da carta régia um importante fato, o terremoto que atingiu Lisboa em 1755, sua divulgação no noticiário português, as repercussões econômicas e sociais desse acontecimento na vida dos habitantes do Brasil colônia, e o posicionamento dos representantes da metrópole na Vila Real do Sabará em favor dos interesses dos colonos brasileiros. 


\section{O MANUSCRITO}

No dia 16 de dezembro de 1755, em Belém, Lisboa, Portugal, uma carta de apenas um fólio, recto e verso, endereçada aos oficiais da Câmara da Vila Real do Sabará, capitania de Minas Gerais, Brasil, é assinada pelo rei de Portugal, D. José I, conforme protocolo da época: "Rey". De forma direta e objetiva, a carta narra um terremoto, seguido de incêndios, que em cinco minutos arruinou templos, palácios, tribunais, alfândegas e edifícios particulares, e sepultou pessoas da cidade de Lisboa e de "todos os estados". Atribuindo essa tragédia a um aviso de Deus, o rei confidencia que resolveu contar logo aos seus leais vassalos, para que pudessem compartilhar tão justificado sentimento de empatia diante da tragédia e, como partes do corpo que se completam com a cabeça, servi-lo com tudo o que fosse possível para a reedificação da cidade.

Pela urgência da demanda, a carta não tardou a chegar. Entre a data do terremoto e a reunião do governador de Minas Gerais, José Antonio Freire de Andrade, com os procuradores de todas as câmaras da capitania, no dia 06 de julho de 1756, quando já estavam sendo decididas as formas de cobrança e a validade do subsídio voluntário ${ }^{1}$, tinham se passado apenas oito meses.

Vinte e um anos depois do início do atendimento ao pedido de ajuda do rei, essa carta foi copiada, no dia 29 de julho de 1777, agora para ser anexada a uma representação, documento diplomático em que os oficiais da câmara da Vila Real do Sabará se dirigiam à então rainha de Portugal, D. Maria I, argumentando que não seria mais possível manter o subsídio voluntário, instituído para a reconstrução de Lisboa; principalmente pela situação decadente em que se encontrava o povo e a capitania, mas também porque o subsídio, estabelecido pelo prazo de dez anos, já havia sido prorrogado por outros dez, conforme deixava-se ler nos demais documentos anexos, e mesmo assim continuava sendo cobrado, segundo eles, indevidamente.

A essa cópia da carta régia, manuscrita em 1777, é que se refere este estudo. O próprio título no manuscrito - Cópia da Carta Regia ao Juiz e officiais da Camara para a contribuiçaõ do subsidio voluntario - evidencia a sua forma: um documento pós-original, último estágio das possibilidades da tradição documental; uma cópia (em latim exemplum, sumptum, translatum), que representa um documento formalmente idêntico ao original; autorizada, produzida a pedido do juiz e oficiais da Câmara da Vila Real do Sabará, com os mesmos efeitos do original; heterógrafa, pois está validada por outra autoridade; um traslado, pois conta com a fé notarial, assim se suprindo da força jurídica do original (Bellotto, 2002, p. 107-108).

Conforme consulta ao site do Arquivo Histórico Ultramarino², há um segundo testemunho dessa cópia de carta régia, anexado ao documento principal do códice, ou seja, a representação de 1777. Essa informação será utilizada neste estudo apenas como hipótese sobre a tradição dos testemunhos, não sendo o objetivo, neste momento, a descrição das variantes entre eles.

\footnotetext{
${ }^{1}$ Conforme descrito no termo em junta também anexo ao códice do qual faz parte a carta régia.

${ }^{2}$ Disponível para consulta em: http://resgate.bn.br/docreader/docmulti.aspx?bib=resgate.
} 


\section{ANÁLISE CODICOLÓGICA}

Segundo Cambraia (2005, p. 26 e 27), analisar os aspectos da confecção material de um códice para compreender as formas do processo de transmissão do texto é atribuição da Codicologia. Para tanto, ter um manuscrito em mãos torna-se condição desejada por todo pesquisador e um privilégio do qual se pode usufruir neste estudo, pois a consulta à cópia da carta régia foi feita por observação direta do documento, catalogado no IEB, cujo acervo é formado por um expressivo conjunto de fundos pessoais - constituídos em vida por artistas e intelectuais brasileiros - e que estão distribuídos entre o Arquivo, a Biblioteca e a Coleção de Artes Visuais ${ }^{3}$.

Para facilitar o acesso ao arquivo, o IEB disponibiliza seu Catálogo Eletrônico on-line. No caso desta pesquisa, foram acessadas as abas: acervo/arquivo/catálogo online/Alberto Lamego. Para consultar o documento diretamente no IEB, é necessário agendar previamente a visita por e-mail.

\subsection{As marcas da trajetória do manuscrito}

Armazenada na Caixa 28, em condições recomendadas de preservação, a carta régia é localizada no IEB pelo código AL-014-002 na Coleção Alberto Lamego. A observação desse códice, onde se insere a carta régia em estudo, remete às reflexões trazidas por Almada (2014, p. 141) de que as marcas deixadas nos suportes são informações preciosas sobre as formas de uso, apropriação, circulação e práticas de preservação do testemunho escrito. No manuscrito em estudo, as marcas são muito evidentes. Basta atentar à cuidadosa e responsável guarda do códice no arquivo do IEB, à encadernação bem feita pelo colecionador, ao carimbo da Biblioteca Central da Faculdade de Filosofia, Ciências e Letras e às anotações tardias, presentes no suporte material, todas informações valiosíssimas sobre as condições de preservação nos seus lugares de pouso.

Papel, tinta e pena de boa qualidade, utilizados por escrivão hábil, na produção da cópia da carta régia, são desvelos que conferem, logo no ato da produção, garantias de validade e longa duração para o documento. Afinal, a documentação, inclusive essa cópia, que seria encaminhada à rainha, demandava apropriada formalidade. Para completar o ritual de confecção, a cópia foi lavrada por escrivão autorizado, a pedido do juiz e oficiais da Câmara, e validada por tabelião, autoridade que confere à cópia a mesma fé notarial e força jurídica do original.

Seguiu-se, ainda, muito provavelmente, o costume da época, de enviar à metrópole mais de uma via do documento, em datas e embarcações diferentes, para evitar o extravio, dada a precariedade das embarcações que transportavam os documentos (Bellotto, 2002, p. 106-107). É possível deduzir isso pela constatação da existência de um segundo testemunho do manuscrito, no Arquivo Histórico Ultramarino. Conforme verificado em consulta ao site do Projeto Resgate ${ }^{4}$, esse testemunho apresenta o carimbo da instituição, o que sugere que uma das vias do documento tenha sido recebida no Conselho Ultramarino.

\footnotetext{
${ }^{3}$ Instituto de Estudos Brasileiros - unidade da USP - http://www.ieb.usp.br/.

${ }^{4}$ https://bndigital.bn.gov.br/dossies/projeto-resgate-barao-do-rio-branco/.
} 
$\mathrm{Na}$ intenção pensada de fazer o manuscrito circular e ser conhecido, desde a sua origem, esses atores da história da preservação da carta régia e de sua cópia encenam como que uma prova de revezamento, em que o documento vai sendo repassado, e cada novo participante desse encadeamento cumpre o seu papel de transmiti-lo à posteridade. Entre o século XVIII, quando a carta régia foi copiada, e o século XXI, momento em que está sendo editada, a trajetória do documento foi marcada, conforme Petrucci $\left(1999^{5}\right.$, apud Almada, 2014), pela fascinante constatação das ações políticas na escolha dos testemunhos escritos da história das sociedades que foram selecionados para serem preservados e acessados pelas elites letradas ou iletradas.

Depois de passar cento e quarenta e três anos em Portugal ${ }^{6}$, o documento retornou ao Brasil em 1920, presumidamente pelas mãos de Alberto Lamego, figura importantíssima na história da preservação do manuscrito. Colecionador, vivendo na Europa durante quatorze anos, adquiriu valiosos documentos relacionados à história do Brasil, de várias instituições, inclusive do Arquivo Histórico Ultramarino: manuscritos, impressos e um vasto repertório iconográfico, que vieram a constituir a sua Biblioteca Brasiliana. Sua casa, em Campos dos Goitacazes/RJ, chamada Solar dos Airizes, abrigou sua coleção por 15 anos. Felizmente, o manuscrito sobreviveu aos possíveis incidentes comuns em arquivos domiciliares, como os ataques destrutivos de insetos.

Em 1935, por sugestão de Mário de Andrade, então chefe do Departamento Municipal de Cultura de São Paulo, a coleção de Alberto Lamego foi adquirida pelo Governo do Estado de São Paulo e entregue à guarda da então fundada Faculdade de Philosofia, Sciências e Letras da Universidade de São Paulo. No seu artigo publicado em 22 de dezembro de 1935, no jornal O Estado de São Paulo, Mário de Andrade transborda sensibilidade ao relatar mais um passo para a preservação da biblioteca Lamego (Nogueira, 2002, p. 16): “Terminou onde devia terminar, no destino mais humano e generoso que podia ter, no regaço duma grande casa de cultura. Já agora ela será de todos, o que é sem dúvida o melhor fim para obras vultosas".

Assim, o manuscrito foi encaixotado e transportado. Viajou do estado do Rio de Janeiro à cidade de São Paulo, tendo sido acomodado, em 1936, nas estantes da Biblioteca Central da USP, no $3^{\circ}$ andar do Edifício Caetano de Campos, na Praça da República.

Somente vinte e cinco anos mais tarde, em 1959, é que o acervo começou a ser catalogado. Em 1961, foi divulgado na Revista de História, por solicitação do professor Eurípedes Simões de Paula à professora Myriam Ellis, o Catálogo da miscelânea e dos manuscritos da Coleção Lamego ${ }^{7}$. Fundamental para esta pesquisa, o catálogo contém informações privilegiadas sobre a história do acervo. Ellis comenta que não houve a pretensão de apresentar um catálogo perfeito, mas apenas de disponibilizar um acervo útil para os pesquisadores. Sem sequer imaginar os recursos tecnológicos que estavam por vir, essas mãos prepararam os documentos para a

\footnotetext{
5 Petrucci A. Alfabetismo, escritura, sociedad. Barcelona: Gedisa Editorial, 1999.

6 Documentação enviada provavelmente do Conselho da Fazenda para o Arquivo dos Próprios Nacionais em data não apurada, por falta de fontes, e incorporada no Arquivo Nacional da Torre do Tombo (ANTT), à época, instalado no Mosteiro de S. Bento da Saúde, em 14 de Maio de 1894.
}

${ }^{7}$ Disponível em: https://doi.org/10.11606/issn.2316-9141.rh.1961.120369. 
impensável tarefa da catalogação digital. A professora Ellis e seus alunos ${ }^{8}$, que participaram dessa árdua tarefa, tornaram-se assim sujeitos políticos nessa nova etapa para a preservação dos documentos.

Em 1968, o manuscrito acompanha o acervo em novo trajeto, desta vez dentro dos limites da cidade de São Paulo. Passa da Faculdade de Filosofia, Ciências e Letras para o Instituto de Estudos Brasileiros da Universidade de São Paulo, onde tem recebido tratamentos profissionais de guarda, conservação e restauro.

Para tornar esse patrimônio histórico e cultural mais visível ao público, especializado ou não, em 1983, as professoras doutoras Heloísa Liberalli Bellotto, Arlinda Rocha Nogueira e Lucy Maffei Hutter organizaram os 4.062 verbetes no Inventário Analítico dos Manuscritos da Coleção Lamego. Em 2002, esse inventário recebeu uma reedição revista e atualizada, e o título: Coleção Alberto Lamego - Catálogo dos Manuscritos, com vários tipos de indices (onomástico, temático, cronológico, toponímico, espécies/formatos documentais e gêneros literários, instituições e equivalência entre códices e rolos de microfilme), que facilitariam a consulta aos documentos. Por fim, todo esse acervo arquivístico foi microfilmado e fotografado, novamente sob a supervisão de Heloísa Liberalli Bellotto. Toda essa documentação está agora disponível para consulta digital nas principais bibliotecas especializadas do Brasil e de Portugal.

\subsection{Os elementos codicológicos}

Em duzentos e quarenta e dois anos, a cópia da carta régia deste estudo fez um percurso de mais de quinze mil quilômetros para atravessar duas vezes o oceano Atlântico, tendo saído de Sabará e chegado a Lisboa; e depois, saindo de Lisboa e chegando ao Rio de Janeiro. Por terra, viajou do Rio de Janeiro a São Paulo. Mesmo assim, encontra-se surpreendentemente bem preservada, acondicionada num códice de $360 \mathrm{~mm}$ de altura por $230 \mathrm{~mm}$ de largura, em encadernação costurada, cuja capa de tecido de juta, na cor rosada, com pequeno furo produzido por inseto, do lado superior esquerdo, ainda mantém sua eficácia na proteção do manuscrito. Conforme informação obtida no catálogo do acervo de 2002, Alberto Lamego mandava encadernar alguns dos documentos de sua Coleção.

O papel, de textura espessa, de boa qualidade, na cor originalmente bege, mas amarelado pelo tempo, apresenta furos, causados por traças, raros e tão pequenos que, até o momento, não impedem a leitura em nenhuma linha dos fólios. De 1 em 1 $\mathrm{mm}$, notam-se as vergaturas, definidas por Ataíde e Melo (1926 - p.11) como raias claras na horizontal, marcadas pelos fios metálicos que constituíam o tear das formas para a fabricação de papel. Perpendicularmente, surgem outras raias claras isoladas, os pontusais, oito por fólio, a cada $26 \mathrm{~mm}$.

Nota-se também no manuscrito a seguinte marca d'água, conforme imagem fotografada (pelos autores) de uma folha em branco do códice, para evidenciar o brasão com árvore no cimo, enfeitada com rolos de papiro, e as letras HCW \&Zoonen, indicando as iniciais do nome do fabricante holandês. Na parte interna, os dois Xx representam a cruz de Santo Andrée:

\footnotetext{
${ }^{8}$ Nomes listados em nota de rodapé, à página 527 do catálogo.

${ }^{9}$ Acessado, em 06/12/2018, o portal eletrônico http://www.bernstein.oeaw.ac.at/ direciona para 'A Memória do Papel', em:

http://www.memoryofpaper.eu:8080/BernsteinPortal/appl start.disp.
} 


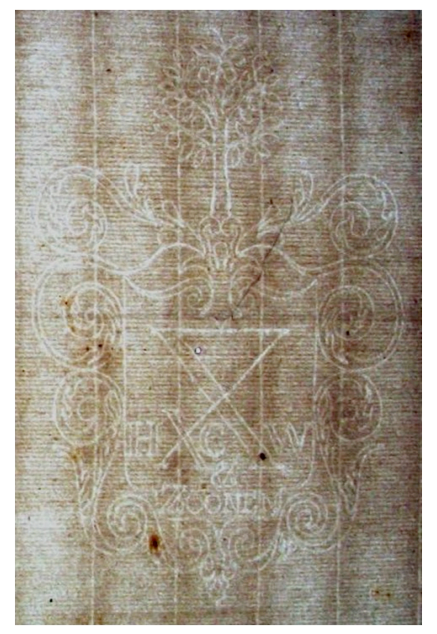

Figura 1 - Marca d'água - Manuscrito do Arquivo do IEB, cota: AL 014-002 (fotografia realizada pelos autores).

No site indicado, foi encontrado o registro das marcas d'água do manuscrito em estudo, com a informação de que circularam entre 1769 e 1777 . A catalogação da referida filigrana em instituição idônea, que registra e disponibiliza marcas d'água de várias partes do mundo, datadas desde o século $\mathrm{XV}$, somada às informações de que até o século XIX Portugal importava papel da Holanda, Inglaterra, França e Itália; de que o papel utilizado no Brasil no século XVIII vinha de Portugal (Oliveira, 2014, p. 59); e da presença dessa marca d'água em documentos escritos em outras capitanias do Brasil, nessa época, conforme estudos de Monte (2007) e Gleyk (2014),validam as datas tópica e cronológica, a primeira, referente à carta original - "Escripta em Belem aos desasseis de Dezembro de mil settecentos cincoenta e cinco", nas linhas 40 e 41 do fólio verso e a segunda, logo a seguir, nos termos de autorização da cópia, à linha 48 - "Sabará e de Julho 29 de 1777".

A pena de ganso, utilizada a partir do século VI, e a tinta ferro-gálica, utilizada desde o século XII, (Berwanger e Leal, 2008), muito provavelmente foram os materiais de escrita desse documento. Esse tipo de tinta melhorou muito o desempenho e a duração da escrita, em relação às tintas antigas, à base de carbono. Entretanto, verificou-se que ela produz, ao longo do tempo, mecanismos de corrosão no papel, os quais têm sido estabilizados a partir da neutralização da acidez da tinta por meios químicos. Felizmente, a tinta utilizada no manuscrito em estudo permanece intacta, e não há manchas indesejadas ou sinais de corrosão no papel por ela causados.

A cópia da carta régia se constitui de 1 fólio opistografado, com as seguintes quantidades de linhas: $1 \mathrm{r}=29 ; 1 \mathrm{v}=25$; cada fólio mede $350 \mathrm{~mm}$ X $220 \mathrm{~mm}$. A mancha ocupa uma coluna de $200 \mathrm{~mm}$ X $125 \mathrm{~mm}$. Há espaço em branco de $150 \mathrm{~mm}$ do topo ao início do texto e de $95 \mathrm{~mm}$ da lateral até a mancha, tanto no folio recto como no folio verso. O manuscrito apresenta reclames, recurso que facilita a recuperação da leitura, já que não se usava ainda a numeração de páginas. A cópia da carta régia ocupa a posição $4 \mathrm{r}$ e $4 \mathrm{v}$, dentre os fólios do códice, porém, neste estudo, utilizada como testemunho único, está numerada como $1 \mathrm{r}$ e $1 \mathrm{v}$. 
$\mathrm{Na}$ margem superior esquerda do fólio recto consta uma anotação tardia, a lápis, a numeração "14.2", indicando o código com que o documento foi cadastrado no catálogo. Podemos deduzir que o arquivista, talvez o profissional que trabalhou na microfilmagem e/ou fotografia dos documentos da Coleção Alberto Lamego, identificou a cópia da carta régia com o número do código do acervo - 14 - seguido do algarismo 2, indicando ser esse o segundo documento constante no códice.

Entre o título e o texto, no recto do primeiro fólio, observa-se um carimbo retangular, medindo $10 \mathrm{~mm}$ X $25 \mathrm{~mm}$, em tinta azul, com os termos: Faculdade de Filosofia, Ciências e Letras - Biblioteca Central, conforme figura 2, abaixo, que comprova a passagem do acervo de Alberto Lamego, onde está inserido o manuscrito, por essa instituição.

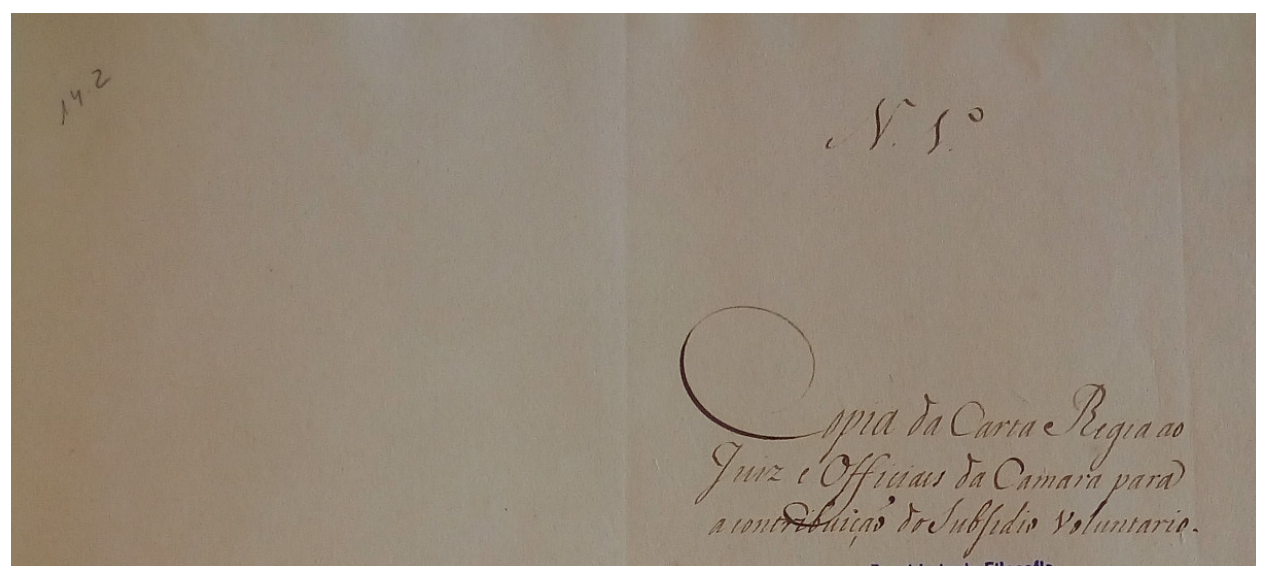

Figura 2 - Anotações tardias - Manuscrito do Arquivo do IEB, cota: AL 014-002 (fotografia realizada pelos autores).

Com as características codicológicas apontadas neste estudo, associadas às análises paleográfica e diplomática, que se seguem, espera-se investigar a genuinidade do manuscrito, marca fundamental para que um texto possa ser utilizado com segurança e credibilidade em futuras pesquisas.

\section{ANÁLISE PALEOGRÁFICA, O TEMPO E O LUGAR DO MANUSCRITO}

O termo Paleografia, modernamente, tem sido utilizado pelos filólogos para definir a decifração e interpretação de manuscritos que apresentem dificuldade de leitura, não apenas os antigos. A análise dos aspectos da escrita, como sua localização e datação, morfologia, traçado das letras, sinais abreviativos, descrição de elementos não-alfabéticos, e também de todo tipo de anotações deixadas no texto (pelo autor, pelo copista, etc.), dentre outros, ajudam o filólogo a avaliar a autenticidade de um documento e a realizar a análise sócio-histórica desse sistema de escrita. Somente após esse estudo detalhado é possível fixar a forma genuína de um texto.

\subsection{Paleografia de leitura}

Contreras (1994, p. 35) propõe uma distinção entre a Paleografia de leitura, a Paleografia de análise e a Paleografia em identidade com a história da escrita, para ampliar a capacidade metodológica de investigação paleográfica. A Paleografia de leitura tem por finalidade a interpretação dos signos. Para tanto, recomenda-se, 
primeiramente, a leitura calma, atenta e minuciosa do manuscrito, passo fundamental para proceder-se, em seguida, à transcrição, que pode ser conservadora ou modernizada, dependendo do público-alvo a que se destina a edição ${ }^{10}$.

Aplicando essa metodologia ao manuscrito em estudo, observamos que a decifração da escrita não oferece grandes dificuldades. $O$ texto foi escrito em português. $O$ alfabeto utilizado, análogo ao sistema gráfico atual, da escrita humanística, permite grande aproveitamento das sílabas, palavras e frases já na primeira leitura. Os traços de cursividade, como a velocidade da escrita e as ligaduras, não chegam a impedir o leitor contemporâneo de ler e compreender os termos da carta. Não há dificuldade, tampouco, na leitura da única abreviatura no texto - "q" — facilmente desdobrada em que, nem léxico tão desconhecido que exija consulta a dicionário especializado.

A maior dificuldade de leitura provavelmente se encontra na identificação dos alógrafos. Para superar esse embaraço, é necessário ordenar o alfabeto utilizado no texto. Definidos os alógrafos, após a elaboração do alfabeto específico do manuscrito em estudo, nota-se pouca diferença entre o modelo mental e a execução da escrita. Ackel (2019), que descreveu o alfabeto para este e para outros manuscritos do acervo do IEB, gentilmente o cedeu para este estudo, o que favoreceu a decifração dos seguintes grafemas:

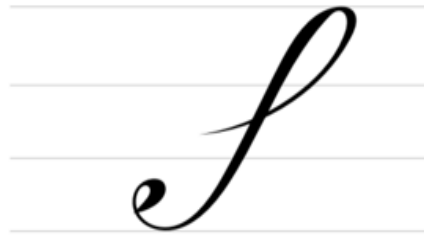

Figura $3-<s>$ inicial

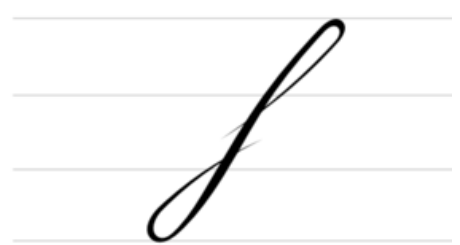

Figura $4-<s>$ medial

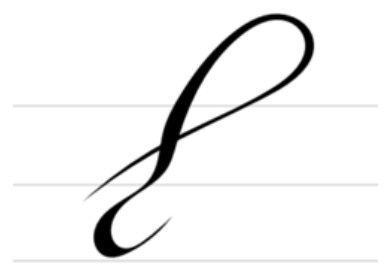

Figura $5-<\mathrm{h}>$ inicial

\subsection{Paleografia de análise}

A Paleografia de análise busca informações sobre a técnica de execução dos vários tipos de escrita, e sobre a datação e localização do documento. O módulo pequeno das letras do manuscrito setecentista, o ductus cursivo, com letras corridas e

\footnotetext{
${ }^{10}$ Editar significa realizar um conjunto complexo de operações das quais fazem parte não apenas a transcrição, mas também a proposição de conjecturas, a seleção de variantes (em uma edição crítica), a apresentação do texto, etc. (Cambraia, 2005, p. 111).
} 
traçadas na maioria sem descanso da mão, a leveza do traçado, o ângulo inclinado à direita, a inexistência de nexos, a frequência de ligaduras, principalmente dos clíticos, e a escassez de abreviaturas seguem o modelo da escrita humanística cursiva ou italiana. A velocidade na execução da escrita não chega a trazer traços de individualização tão fortes que impeçam a decifração das letras.

Chamam também a atenção do leitor determinadas práticas gráficas e ortográficas do século XVIII, presentes no manuscrito setecentista, que podem ser consideradas "fórmulas de escrita de uma pequena parte da sociedade que apresentam considerável regularidade, a ponto de caracterizar o estado da língua naquela fase" (Fachin, 2011, p. 14 e 15). Essas práticas, apenas citadas, já que não constituem objetivo primordial deste estudo, são: as grafias etimologizadas (omnipotente, villa, oficiaes, aquella, nellas, vassallos, promptamente, occasiaõ, elleiçaõ, escripta, settecentos, assignei); o hífen duplo ao final da linha, indicando separação de sílabas; a sinalização do 'til' na vogal <o >, e não na vogal <a>, na formação do ditongo “ão"; o sinal "//" para indicar o encerramento da carta (Rey//) e para delimitar o trecho em que aparece a assinatura do escrivão (//Custodio dos Anjos Fremes//); a falta de regularidade na grafia dos ditongos ey/ei, como em Rey e reinos; o pretérito perfeito e imperfeito com desinência "aõ" e não "am", na $3^{\text {a }}$ pessoa do plural; o til na vogal "u", para indicar nasalidade, como em "hũ"; e palavras escritas como se pronunciam, que podem revelar tanto fenômenos de oralidade, como falta de instrução do escriba: desaseis, terromoto, reideficada.

As datas tópicas e cronológicas são explícitas no documento, tanto no texto original, de 1755, escrito em Belém, Portugal, às linhas 41 e 42 do fólio 1v., quanto na cópia, realizada em 1777, na Vila Real do Sabará, capitania de Minas Gerais, Brasil, à linha 50 do fólio $1 \mathrm{v}$.

\subsection{Paleografia em identidade com a história social da escrita}

Essa análise dos tipos gráficos, da localização e da datação do manuscrito fornece evidências para estudos que se relacionam à Paleografia em identidade com a história social da escrita. Segundo Petrucci $\left(1999^{11}\right.$, apud Sartori, 2018), por difusão social da escrita deve-se entender a capacidade de ler e escrever, já que as sociedades que possuem escrita são formadas por analfabetos e alfabetizados. Podemos inferir que o escrivão da Câmara da Vila Real do Sabará que em 1777 efetuou a cópia da carta régia de 1755 demonstra habilidade, pois reproduz escrita regular quanto ao traçado das letras, homogeneidade do tamanho, respeito à pauta e às linhas imaginárias, sem borrões, nem rasuras.

Com o intento de distinguir, no manuscrito, uma marca personalizada do escrivão, Custódio dos Anjos Fremes, que subscreveu e assinou a primeira via do documento à linha 55, e do tabelião público, Thomas de Aquino Figueiredo, que autenticou o documento, à linha 54, reproduzimos a metodologia de Sartori (2018) para classificação de morfologia das assinaturas ${ }^{12}$. Nota-se que elas apresentam nível médio ou alto de execução gráfica ${ }^{13}$, pela segurança e destreza ao segurar a pena, pelo

\footnotetext{
11 Petrucci A. Alfabetismo, escritura, sociedad. Barcelona: Gedisa Editorial; 1999.

12 Nome de uma pessoa ou a sua representação, feito de próprio punho sobre um documento para indicar sua autoria ou avalizar seu conteúdo.

${ }^{13}$ Critério exclusivo, estabelecido por Sartori (2018, p. 51).
} 
traçado regular, pelo bom alinhamento das letras, pela abundância de ornamentação na escrita, pelas laçadas entre as letras e ainda pelos sinais públicos ao final das assinaturas, conforme figura a seguir, recorte da fotografia da carta régia, realizada pelos autores.

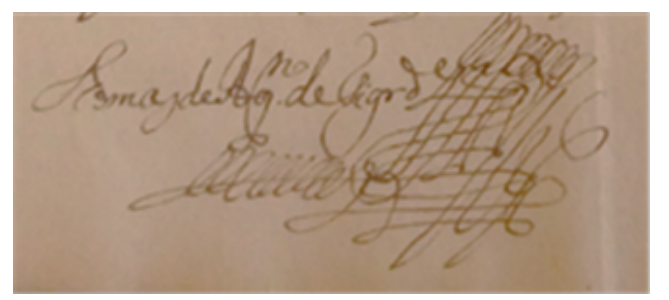

Figura 6 - Morfologia das assinaturas - Manuscrito do Arquivo do IEB, cota: AL 014-002 (fotografia realizada pelos autores).

Quanto à função que a escrita assume na sociedade, Magalhães (2014, p. 302303) explica que a escrituração era informação, ordem, hierarquia, mobilização. Em seu estudo sobre a relação entre escrita e municipalismo no Brasil colônia, ao longo do século XVIII, constata que os municípios foram instâncias de ordenamento, poder e decisão, por estatuto próprio e por delegação régia.

Com esses dados, podemos afirmar que o documento em questão se destaca como um manuscrito do século XVIII, apresentando características codicológicas e paleográficas próprias de seu tempo e lugar.

\section{ANÁLISE DIPLOMÁTICA E OS SINAIS DE AUTENTICIDADE DO DOCUMENTO}

O texto deste estudo se refere a uma carta régia, ou seja, uma ordem real, dirigida a uma determinada autoridade ou pessoa, neste caso, ao juiz e aos oficiais da Câmara da Villa Real do Sabará. Na subscrição "Rey", podemos identificar o soberano pela data da carta régia. Em 1755, o rei de Portugal era D. José I, cujo reinado foi marcado pelas políticas do seu secretário de Estado, o Marquês de Pombal, muito atuante nesse momento do terremoto.

Segundo Bellotto (2002), carta régia é um documento diplomático, ou seja, um testemunho escrito de natureza jurídica, que obedece a fórmulas convencionadas, em geral estabelecidas pelo Direito administrativo ou notarial; dispositivo normativo, ou seja, que manifesta a vontade da autoridade suprema e que deve obrigatoriamente ser acatado pelos subordinados; e descendente, quer dizer, desce do Rei aos súditos, às instâncias inferiores, e até mesmo geograficamente, desce do hemisfério norte para o hemisfério sul, de Portugal para o Brasil. Uma ordem real, dirigida a uma determinada autoridade ou pessoa.

O manuscrito em estudo ilustra a espécie documental tanto na sua forma jurídico-administrativa, como na estrutura textual, que observa as fórmulas de redação estabelecidas. A carta régia, escrita em Belém, no dia 16 de dezembro de 1755, inicia com o protocolo: "Eu, El Rey, vos envio muito saudar"; depois, apresenta o texto: objeto ou tema da carta, que, no caso, é o pedido de ajuda do rei às câmaras da capitania de Minas Gerais, para a reconstrução de Lisboa; e como protocolo final, consta a subscrição: "Rey". 
Essas características, somadas ao fato de que a Câmara da Vila Real do Sabará enviou o subsídio voluntário à metrópole por sessenta anos, conforme informação reproduzida de documentos catalogados no Arquivo Público de Minas Gerais ${ }^{14}$, acatando, como subordinada, a vontade da autoridade suprema, fortalecem a hipótese de se tratar de um documento autêntico.

É preciso ressaltar, entretanto, que o objeto deste estudo é a cópia da carta, que foi produzida em 29 de julho de 1777, a pedido dos juízes e oficiais da Câmara da Vila Real do Sabará. Por isso, tratada pela tradição documental, é classificada como um pós-original, último estágio da transmissão de um documento, uma cópia, ou a primeira via, que conviveu com seu original ainda existente. (Bellotto, p. 107108). Chamada de heterógrafa, pois foi elaborada e validada por outro escrivão, que não o da carta original, conforme transcrição do referido manuscrito, linhas 43 a 50:

\footnotetext{
Para o Juiz Vereadores, e officiaes da Camara da Villa do Sabará. Primeira via Custodio dos Anjos Fremes Escrivaõ da Comarca que o sobscrevi e asignei// Custodio dos Anjos Fremes// E mais se naõ continha em o dito registro da Carta Regia de que passa o referido em Verdade. Sabará e de Julho 29 de 1777.
}

Uma cópia autorizada, numerada pelo escrivão como anexo $\mathrm{N} 1^{\circ}$, e que surte os mesmos efeitos do original, do tipo traslado, com a fé notarial: E eu Thomas de Aquino de FigueiredoTabaliaõ do publico judicial e notas que o sobescrevi e asiney. As assinaturas do escrivão Custódio dos Anjos Fremes e do tabelião Thomas de Aquino de Figueiredo, identificadas com sinais públicos, reforçam a força jurídica do original na cópia. Como cópia a ser inserida na representação, a carta régia de 1755 assume uma nova função, a de comprovar as argumentações dos oficiais da Câmara da Vila Real do Sabará.

Enfim, esta breve análise diplomática do documento, relacionada com os dados codicológicos e paleográficos anteriormente apresentados, permite inferir que a autoria, a datação, a autenticidade das assinaturas e a forma de transmissão do manuscrito conferem-lhe a condição de documento contemporâneo e muito relevante na dinâmica administrativa colonial do século XVIII; principalmente por configurar um meio eficaz de comunicação do próprio Rei com os seus súditos, garantindo que as leis escritas fossem cumpridas, apesar da distância entre a metrópole e a colônia.

\section{CONTEXTUALIZAÇÃO HISTÓRICA: AS REPERCUSSÕES DO TERREMOTO}

O texto do manuscrito se transforma em instrumento que revela, de maneira particular, a história oficial do terremoto que assombrou o povo de Lisboa, pela sequência de grande tremor de terra, de incêndios, e de ondas gigantes, as quais, segundo a carta régia, em cinco minutos arruinaram os templos, os palácios, os tribunais e as alfândegas, consumindo grande número de pessoas.

A notícia do terremoto foi anunciada no periódico intitulado Gazeta de Lisboa, consultado na Coleção Alberto Lamego, do $\mathrm{IEB}^{15}$ : “O dia 1. ${ }^{\circ}$ do corrente ficará

\footnotetext{
14 1813-1816 Registro dos bilhetes do Subsídio Voluntário. CMS-148 Rol. 20 - Prat. O-17.

15 Código de Ref.: AL-062-025 - Caixa 44 - Códices 059, 060, 061 e 062 (Sala 1).
} 
memorável a todos os séculos pelos terramotos e incêndios que arruinaram uma grande parte desta cidade; mas tem havido a felicidade de se acharem na ruína os cofres da fazenda real e da maior parte dos particulares". A seguir, recorte do mesmo periódico, do dia 13 de novembro de 1755, relatando que a Torre do Tombo, importante guardiã da documentação colonial, também fora atingida pelos efeitos do terremoto; e a sua transcrição, realizada pelos autores:

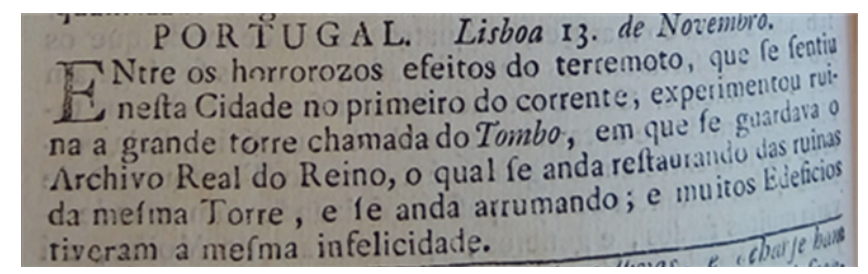

Figura 7 - Gazeta de Lisboa - Arquivo IEB - AL-062-025 (fotografia realizada pelos autores).

PORTUGAL. Lisboa 13. de Novembro.

ENtre os horrorozos efeitos do terremoto, que se sentiu nesta Cidade no primeiro do corrente, experimementou ruina a grande torre chamada do Tombo, em que se guardava o Archivo Real do Reino, o qual se anda restaurando das ruinas da mesma Torre, e se anda arrumando; e muitos Edeficios tiveram a mesma infelicidade.

Já a cópia da carta régia contextualiza uma nova situação, uma nova relação da Câmara da Vila Real do Sabará com a metrópole. A princípio, assim que a carta régia fora recebida, os oficiais se reuniram para decidir os termos do atendimento ao pedido de ajuda para a reconstrução de Lisboa. Decidiram que o imposto vigeria por dez anos. Ao final desse prazo, houve uma solicitação de prorrogação pelo governador, por mais dez anos, porém o auto de vereação de 19 de outubro de 1768 reduziu a porcentagem dos valores que seriam arrecadados para esse imposto, e deixou claro que, ao fim dos dez anos, ou seja, em 1778, sem haver necessidade de qualquer comunicação ao governador ou à rainha, a cobrança cessaria, automaticamente. Aproximando-se essa data, e temendo se repetisse a prorrogação da cobrança, os oficiais da câmara da Vila Real do Sabará se antecipam para lembrar à metrópole que, devido à situação precária em que se encontrava a população na capitania de Minas Gerais, e também porque a Câmara já havia cumprido os prazos anteriormente estabelecidos por escrito, conforme documentos válidos e anexos, inclusive a cópia da carta régia, não mais enviariam o subsídio voluntário. Para comprovar os termos da representação, anexaram as seguintes cópias: da carta régia de 1755; do termo em junta de 1756; e do auto de vereação de 1768.

Segundo Russel-Wood (1998, p.189 e 192), os governantes

\footnotetext{
descobriam-se frequentemente no papel de mediadores entre a implementação da vontade real e os interesses locais. [...]

E os colonos, longe de serem partes passivas nas relações metrópolecolónia ou centro-periferia, desde Macau a Minas Gerais, faziam ouvir as suas vozes e exerciam pressões que modificavam ou, em certos casos, contrariavam as intenções reais.
} 


\section{A EDIÇÃo SEMIDIPLOMÁTICA}

Com o objetivo de oferecer a todos os tipos de leitores a oportunidade de contemplar o retrato do documento físico, optou-se pela apresentação da edição facsimilar antes da edição semidiplomática. Apesar do conservadorismo da edição, que segue as normas de transcrição de documentos manuscritos e impressos do Projeto para a História do Português Brasileiro (Megale e Toledo Neto, 2005), a mediação dos editores na modernização dos casos de fronteiras de palavras favorece a leitura ao público menos especializado. Além disso, na edição:

1. As abreviaturas serão desenvolvidas, marcando-se - em itálico - as letras omitidas, respeitando a grafia do manuscrito;

2. A pontuação original será rigorosamente mantida.

3. A acentuação original será rigorosamente mantida, inclusive a sua posição, não se permitindo qualquer alteração;

4. Será respeitado o emprego de letras maiúsculas e minúsculas, como se apresentam no original. No caso de alguma variação física dos sinais gráficos resultar de fatores cursivos, não será considerada relevante. Assim, a comparação do traçado da mesma letra deve propiciar a melhor solução;

5. Eventuais erros do escriba ou do copista serão remetidos para nota de rodapé, ao lado da lição correta, da seguinte forma: "epaço" por "espaço";

6. Intervenções de terceiros no documento original serão indicadas em nota de rodapé;

7. A divisão das linhas do documento original será preservada, ao longo do texto. A mudança de fólio receberá a marcação com o respectivo número na sequência de duas barras verticais: || $1 \mathrm{r}|||| 1 \mathrm{v}||$.

8. As linhas serão numeradas de cinco em cinco, a partir da quinta. Essa numeração será encontrada à margem direita da mancha, à esquerda do leitor. Será feita de maneira contínua por documento.

9. As assinaturas simples ou rubricas serão sublinhadas. Os sinais públicos serão sublinhados e indicados entre colchetes. Exemplo: assinatura simples Bernardo Jose de Lorena; sinal público - [ernardo Jose de Lorena];

10. Os alógrafos contextuais de caracteres serão uniformizados segundo o alfabeto atual. 


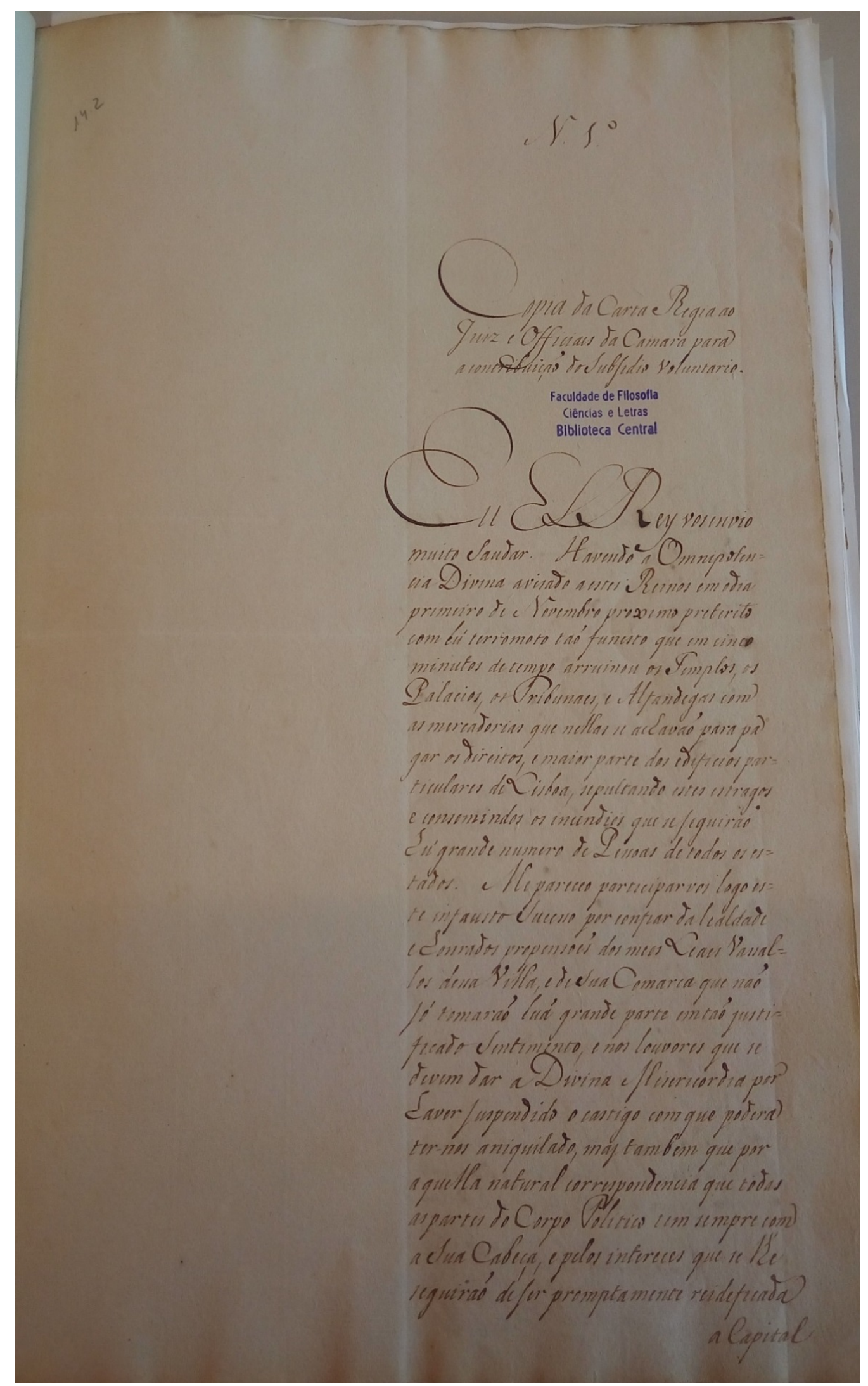

Figura 8 - Fotografia do fólio 1 recto da carta régia, realizada pelos autores. 


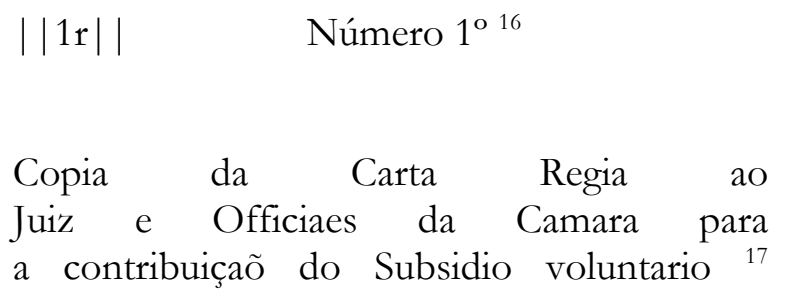

$5 \mathrm{Eu} \quad \mathrm{El} \quad \mathrm{Rey}$ vos envio muito saudar. Havendo a Omnipoten= cia Divina avisado a estes Reinos em o dia primeiro de Novembro proximo preterito com hũ terromoto taõ funesto que em cinco 10 minutos de tempo arruinou os Templos, os Palacios, os Tribunaes, e Alfandegas com as mercadorias que nellas se achavaõ para pa gar os direitos, e maior parte dos edificios par= ticulares de Lisboa, sepultando estes estragos

15 e consomindos ${ }^{18}$ os incendios que se seguiraõ hũ grande numero de Pessoas de todos os es= tados. Me pareceo participar vos logo es= te infausto Sucesso por confiar da lealdade e honrados propensoẽs dos meos Leaes Vassal=

20 los dessa Villa, e de sua Comarca que naõ só tomaraõ huã grande parte em taõ justi= ficado Sentimento, e nos louvores que se devem dar a Divina Misericordia por haver suspendido o castigo com que podera 25 ter-nos aniquilado, mas tambem que por aquella natural correspondencia que todas as partes do Corpo Politico tem sempre com a Sua Cabeça, e pelos intereces que se lhe seguiraõ de ser promptamente reideficada

a Capital

\footnotetext{
16 Presença de anotação tardia: 14.2, a lápis, na margem esquerda superior, na altura da linha onde consta "N. 1 "'.

17 Abaixo desta linha há a presença de carimbo retangular: Faculdade de Filosofia Ciências e Letras Biblioteca Central.

18 consomindos ] consomindo.
} 


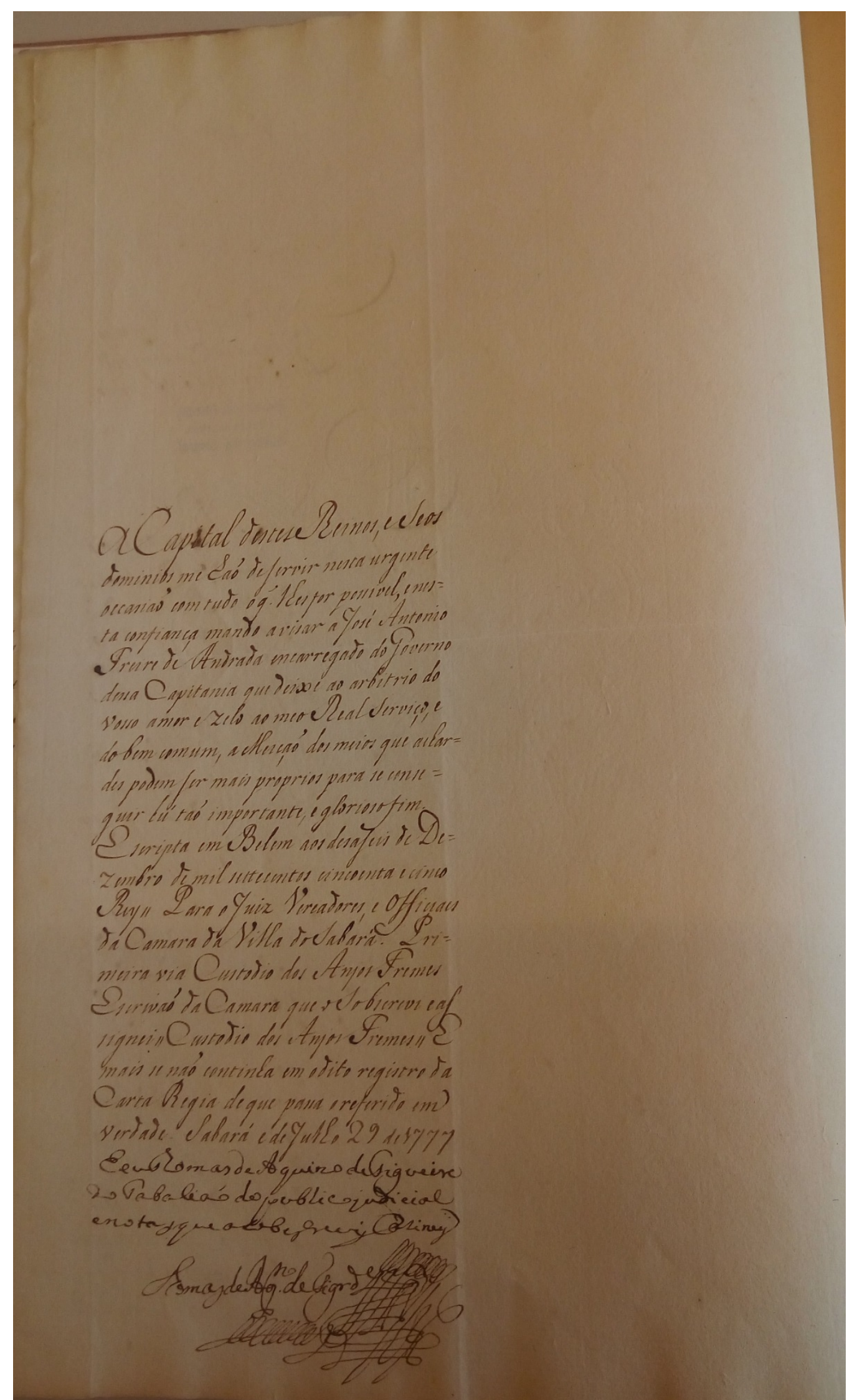

Figura 9 - Fotografia do fólio 1 verso da carta régia, realizada pelos autores. 
|| $1 \mathrm{v}|| \mathrm{a}$ Capital destes Reinos, e Seos dominios me haõ de servir nesta urgente occasiaõ com tudo o que lhes for possivel, e nes= ta confiança mando avisar a Jose Antonio

35 Freire de Andrada encarregado do Governo dessa Capitania que deixe ao arbitrio do vosso amor e zelo ao meo Real Serviço, e do bem comum, a elleiçaõ dos meios que achar= des podem ser mais proprios para se conse $=$

40 guir hũ taõ importante, e glorioso fim. Escripta em Belem aos desaseis de $\mathrm{De}=$ zembro de mil settecentos cincoenta e cinco Rey // Para o Juiz Vereadores, e Officiaes da Camara da Villa do Sabará. Pri=

45 meira via Custodio dos Anjos Fremes Escrivaõ da Camara que o Sobscrevi e as signei// Custodio dos Anjos Fremes// E mais se naõ continha em o dito registro da Carta Regia de que passa o referido em

50 Verdade. Sabará e de Julho 29 de 1777 E eu Thomas de Aquino de Figueire do Tabaliaõ do publico judicial e notas que o Sobescrevi e asiney [Thomas de Aquino de Figueiredo] 


\section{CONSIDERAÇÕES FINAIS}

O caminho percorrido pela Coleção Alberto Lamego, da qual faz parte o documento deste estudo, apenas um dentre tantos exemplos, deixa transparecer a intencionalidade de se preservar e transmitir documentos a gerações futuras. Todos esses cuidados com o manuscrito ratificam a alusão da historiadora Silvia Lara (2008, p. 22):

\footnotetext{
Alguns historiadores alertam ainda que, além do gesto da escrita, da produção do texto e do que eles registram, é preciso pensar também no longo caminho que fez com que aquele texto chegasse até os dias de hoje. De fato, como afirmei anteriormente, "depois de escritos, por motivos e com fins variados, os textos são guardados ou descartados segundo critérios que faziam sentido para os homens e mulheres do passado e, depois deles, para os profissionais responsáveis por sua preservação.
}

Valendo-se do aparato teórico da Codicologia, da Paleografia e da Diplomática, a análise filológica do manuscrito setecentista, realizada pela perspectiva da curadoria textual, resultou na edição fac-similar e semidiplomática da cópia da carta régia dirigida ao juiz e aos oficiais da Câmara da Vila Real do Sabará. Dessa forma, espera-se ter contribuído para a divulgação desse patrimônio cultural escrito, para a preservação material do documento, publicado em novo suporte, e também para a sua utilização pelos pesquisadores que dele se podem valer com fiabilidade para os mais variados tipos de estudos científicos.

\section{REFERÊNCIAS}

Ackel A. Estudo paleográfico de manuscrito do século XVII. Todas as letras - Revista de Língua e Literatura, 2019;21:1-23.

Almada M. Cultura escrita e materialidade: possibilidades interdisciplinares de pesquisa. Pós, 2014;4(8): 134-147.

Bellotto HL. Como fazer análise diplomática e análise tipológica de documentos de arquivo. São Paulo: Arquivo do Estado e Imprensa Oficial do Estado; 2002.

Berwanger AR , Leal JEF. Noções de paleografia e diplomática - 3. ed. rev. e ampl. Santa Maria: Ed. da UFSM; 2008.

Cambraia CN. Introdução à crítica textual. São Paulo: Martins Fontes; 2005.

Contreras LN. Manual de paleografía. Madrid: Cátedra; 1994.

Ellis M. Catálogo da miscelânea e dos manuscritos da coleção Lamego. Revistas USP, 1961;22(46):521-542. [citado 17 jul. 2020]. Disponível em: https://doi.org/10.11606/issn.23169141.rh.1961.120369.

Fachin PRM. Práticas de escrita setecentista em manuscritos da administração colonial em circulação pública no Brasil [tese]. São Paulo: Faculdade de Filosofia, Letras e Ciências Humanas, Universidade de São Paulo; 2011. doi:10.11606/T.8.2011.tde-01112011-131748.

Lara SH. Os documentos textuais e as fontes do conhecimento histórico. Anos 90, 2008;15(28):17-39. 
Magalhães J. Escrita e Municipalismo na transição do Brasil-colónia e na ideação do Brasil independente. Revista de História Regional, 2014;19(2). doi:10.5212/Rev.Hist.Reg.v.19i2.0003.

Megale H, Toledo Neto S de A. Por minha letra e sinal: documentos do ouro no século XVII. Cotia: Ateliê Editorial, FAPESP; 2005.

Melo AFA. O papel como elemento de identificação. Lisboa: Biblioteca Nacional; 1926.

Monte VM. Documentos setecentistas: edição semidiplomática e tratamento das sibilantes [dissertação]. São Paulo: Faculdade de Filosofia, Letras e Ciências Humanas, Universidade de São Paulo; 2007.

Nogueira AR, Bellotto HL, Hutter LM. Catálogo dos manuscritos Coleção Alberto Lamego. 2a . ed. São Paulo: IEB. EDUSP; 2002.

Oliveira GGM. Estudo do papel e das filigranas dos séculos XVIII e XIX na capitania e província de Mato Grosso. Cuiabá/MT [dissertação]. Cuiabá: Universidade Federal de Mato Grosso; 2014.

Russel-Wood AJR. Governantes e agentes. In: Bethencourt, Francisco e Chaudhuri, Kirti (dir.). História da expansão portuguesa. O Brasil na balança do Império (1697-1808). Lisboa: Círculo de Leitores; 1998.

Sartori A. Níveis de execução gráfica no Brasil quinhentista: uma análise da morfologia das assinaturas deixadas nos livros da inquisição. In: Lose AD, Souza AS. Paleografia e suas interfaces. Salvador: Memória \& Arte; 2018. 